\title{
Revisiting Concepts and Theories in Information Systems and Technology
}

\section{Weng Marc Lim}

Swinburne University of Technology

lim@wengmarc.com / marclim@swin.edu.au / wlim@swinburne.edu.my

Information system is both a product and a discipline. As a product, information system consists of a set of interrelated components-for example, hardware, software, people, process, and data - that work together to provide value to firms, such as useful information for informed decision-making. As a discipline, information system is the study of entities and events characterizing its product form.

In revisiting the disciplinary perspective, it is important to note that most concepts and theories in information systems and technology (e.g. information systems success model, technology acceptance model) are not only interrelated but also conceived when mainstream society received initial exposure to digital technologies (e.g. computers, the Internet) in applied settings (e.g. e-procurement, e-commerce).

Given the rapid proliferation in the technology advancement and usage of, as well as access and exposure to, information systems over time, a research notes special section in the Australasian Journal of Information Systems was commissioned to encourage scholars in the field to revisit existing concepts and theories in information systems and technology. Specifically, research notes in the special section offer fresh insights on how the conceptual boundaries of and methodological approaches to utilize these concepts and theories can be expanded and/or reconfigured so as to maintain currency and relevance in the pursuit of advancing theory and practice in the area.

All accepted research notes in the special section, which had undergone a series of doubleblind peer reviews, introduce an existing concept or theory in information systems and technology, explain its limitations with respect to understanding recent trends in information systems and technology, and offer well-articulated solutions to address or mitigate those limitations so as to facilitate greater theoretical and practical development and understanding of information systems and technology in the contemporary era.

The article by Gupta et al. (2018) reveals that there are two resource-based views (RBVs) of information systems: conventional and contemporary. The conventional RBV of information systems suggests that firms use information systems as a firm resource to establish sustainable competitive advantages and drive firm performance, particularly in stable business environments. Meanwhile, the contemporary RBV of information systems takes into account the peculiarities of agile and dynamic business environments, thus encouraging firms to use information systems as a firm resource to establish transient competitive advantages and drive firm performance.

The rejoinder by Lim (2018) addresses some of the most pertinent issues confronting the technology acceptance model (TAM) by reviewing the model's critiques and responding to those critiques with dialectic antidotes in the form of conceptual, methodological, and replication treatments. These treatments, which are useful and relevant for behavioural modelling, support the continued use of the TAM to understand the peculiarities of user interactions with technology in technology-mediated environments. 
The manuscript by Namvar et al. (2018) introduces sensemaking as an approach to deal with complicated, complex, and chaotic data. The authors acknowledge and consolidate the essence of diverse sensemaking perspectives in the extant literature into a simplified blueprint. This blueprint is positioned as a reference point that can be used by scholars to gain an understanding of the concept, process, strengths, and shortcomings of sensemaking, as well as the relevant ways forward for its use with regard to information systems in contemporary business environments.

The research note by Samhan (2018) spells out extant conceptualization, contextualization, antecedents, interventions, and consequences of current and future work on technology resistance. The author makes the case that technology resistance can assume multiple forms, and thus necessitates greater research using multiple theoretical lenses and perspectives. These contentions and underpinnings are explained in the main text and depicted in a succinct and sharp illustration by the author.

The paper by Taxén (2018) examines sociomateriality, a niche but important concept in the field of information systems. The author elucidates the limitations of the predominant strand of sociomateriality-that is, strong sociomateriality-and proposes a reconfiguration of sociomateriality from a neurobiological perspective, which encapsulates assumptions pertaining to the dialectical ontology, the substantialist aspect (or the relata), and the processual aspect (or the dialectics between relata). The author argues that the extreme relational ontology of strong sociomateriality is an untenable foundation for information systems research and that the product of a neurobiological reconfiguration, including alternative variants such as weak sociomateriality and imbrication, should be considered, where individuals should be included as prime constituents, alongside the social and the material, in information systems.

Special thanks to everyone who have contributed to the publication of the special issue, namely:

1. The Editor-in-Chief for accepting the proposal for the special section as well as his ongoing support toward its publication, including leading a separate independent review process for the section editor's submission: John Lamp, Deakin University.

2. The authors who have contributed intellectual insights and endured the lengthy but rigorous review process for the special section: Jacob Cybulski, Deakin University; Yaw Seng Ee, Swinburne University of Technology; Gaurav Gupta, Indian Institute of Management; Morteza Namvar, University of Wollongong; Cynthia Su Chen Phang, Swinburne University of Technology; Bahae Samhan, Illinois State University; Kevin Tee Liang Tan, Swinburne University of Technology; and Lars Taxén, Linköping University.

3. The reviewers who have tirelessly contributed to reviewing and re-reviewing the submissions for this special section: Nabeel Al-Qirim, United Arab Emirates University; Rui Bi, Charles Sturt University; Chin Chen, National University of Taipei; Ranko Cosic, University of Melbourne; Helen Hasan, University of Wollongong; Yong Jin Park, Howard University; Kai Riemer, University of Sydney; Stephen Smith, Macquarie University; Siri Wassrin, Linköping University; Yancong Xie, Queensland University of Technology; and Orkun Yildiz, Gazi Üniversitesi. 
Lastly, it is hoped that the insights from the special section will accelerate the advancement and impact of information systems and technology theory and practice. Further extensions and post-publication reviews of papers in this special section are encouraged and welcomed on the basis of academic collegiality and freedom for knowledge advancement.

\section{Weng Marc Lim}

Head of School, School of Business, Swinburne University of Technology

Section Editor, Australasian Journal of Information Systems

Ranked "A" by the Australian Business Deans' Council and the Australian Council of Professors and Heads of Information Systems

\section{References}

Gupta, G., Tan, K. T. L., Ee, Y. S., \& Phang, C. S. C. (2018). Resource-Based View of Information Systems: Sustainable and Transient Competitive Advantage Perspectives. Australasian Journal of Information Systems, 22.

Lim, W. M. (2018). Dialectic Antidotes to Critics of the Technology Acceptance Model: Conceptual, Methodological, and Replication Treatments for Behavioral Modeling in Technology-Mediated Environments. Australasian Journal of Information Systems, 22.

Namvar, M., Cybulski, J. L., Phang, C. S. C., Ee, Y. S., \& Tan, K. T. L. (2018). Simplifying Sensemaking: Concept, Process, Strengths, Shortcomings, and Ways Forward for Information Systems in Contemporary Business Environments. Australasian Journal of Information Systems, 22.

Samhan, B. (2018). Revisiting Technology Resistance: Current Insights and Future Directions. Australasian Journal of Information Systems, 22.

Taxén, L. (2018). Reconfiguring Sociomateriality from a Neurobiological Perspective. Australasian Journal of Information Systems, 22.

Copyright: (C) $2018 \mathrm{Lim}$. This is an open-access article distributed under the terms of the Creative Commons Attribution-NonCommercial 3.0 Australia License, which permits noncommercial use, distribution, and reproduction in any medium, provided the original author and AJIS are credited.

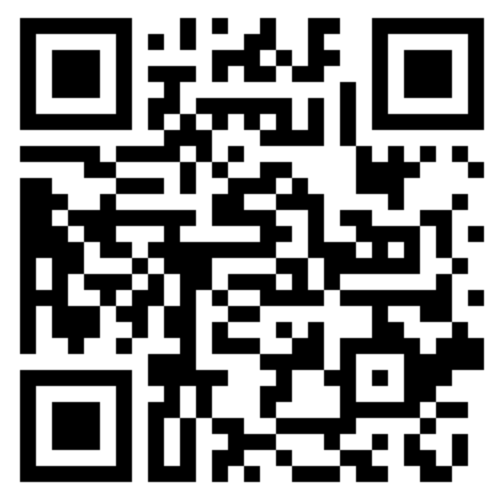

